\title{
Immunoregulation of Lymphokine-Activated Killer Cells ${ }^{1}$
}

\author{
Madhavan P. N. Nair and Stanley A. Schwartz \\ Departments of Pediatrics and Epidemiology, The University of Michigan, \\ Ann Arbor, Michigan 48109
}

\begin{abstract}
The in vitro effects of Concanavalin A (Con A) and prednisolone (PRD) on the cytotoxic functions of lymphocytes and the generation of lymphokine-activated killer (LAK) cells were investigated. Con A at concentrations ranging from 1 to $40 \mu \mathrm{g} / \mathrm{ml}$ did not significantly affect the cytotoxicity of LAK cells when added directly to the effector and target cell mixture in a $4-\mathrm{hr}{ }^{51} \mathrm{Cr}$ release assay. The generation and lytic capacity of LAK cells were significantly affected by Con $\mathrm{A}$ in a dose-dependent manner when lectin was added at the initiation of culture. Suppression of LAK cell activity was demonstrable at different effector:target (E:T) cell ratios. Lymphocyte cultures incubated with PRD at concentrations ranging from $10^{9}$ to $10^{4} M$ showed a decrease in both the numbers of and activity of LAK cells using a variety of target cells. Pretreatment of target cells with either PRD or Con A did not affect their sensitivity to lysis by LAK cells and incubation of lymphocytes with Con A did not induce autoreactive cytotoxic or suppressor cells directed against LAK cell activity. Thus while PRD and Con A can inhibit the generation of LAK cells, they also directly inhibit their specific cytotoxic activity on a per cell basis. These results suggest that like other cytotoxic cells. LAK cells are also under active immunologic control. (1) 1988 Academic Press. Inc.
\end{abstract}

\section{INTRODUCTION}

Cytotoxic lymphocytes play a significant role in host surveillance against malignant and virus-infected cells (1-3). Studies have shown that cytotoxic cells, themselves potentially immunoregulatory, are also under active immunologic control (4-7). We reported earlier that human lymphocytes precultured with Concanavalin A (Con A) showed significantly decreased levels of natural killer (NK) and antibody-dependent cellular cytotoxic (ADCC) activities and expressed suppressor effects on the NK and ADCC activities of autologous and allogeneic lymphocytes (8). Corticosteroids, accepted therapy for various autoimmune and allergic diseases, can affect a variety of immune functions in man. Our previous studies demonstrated that prednisolone (PRD) significantly inhibited the NK and ADCC activities of human lymphocytes (5) and PRD-activated lymphocytes produccd lymphokine(s) which can suppress the cytotoxic activities of allogeneic cells (9).

Recently Rosenberg et al. $(10,11)$ described a cytotoxic lymphocyte subpopulation which can be expanded in vitro by treatment with interleukin 2 (IL-2). These cells, which have increased cytotoxic activities, are called lymphokineactivated killer cells or LAK cells. LAK cells are active against a variety of autologous, allogeneic, and xenogeneic tumor cells which are normally resistant

\footnotetext{
' This work was supported, in part, by NIH Grant 5-RO1-CA35922, NIH Biomedical Research Support Grant 2-SO7-RR05383, and by a research grant from Hoffman LaRoche Co., Inc. Dr. Schwartz is a recipient of NIH RCDA Award No. 5-KO4-CA00896.
} 
to lysis by NK cells (12-14). Another lymphocyte subpopulation that appears to be 50 to 100 times more potent than LAK cells has also been described, namely tumor infiltrating lymphocytes (TIL) (15). LAK effector cells appear to be different from NK, ADCC, or lectin-dependent cellular cytotoxic cells (LDCC) (14) and are derived from phenotypically heterogeneous precursors $(16,17)$. Adoptive immunotherapy with LAK cells and IL-2 has resulted in regression of various human tumors (10); however, this form of treatment has been associated with some undesirable side effects (18). The administration of steroids was noted to diminish some of these toxic effects, and cortisone acetate also reduced the in vivo toxic effect of high doses of IL-2 (18). If LAK cells are potentially immunoregulatory it is reasonable to speculate that these cells are also under active immunoregulation. The present experiments were designed to investigate whether Con A and PRD, two agents capable of regulating NK activity, can also modulate the generation and function of LAK cells in vitro.

\section{MATERIALS AND METHODS}

\section{Media}

Complete medium consisted of RPMI 1640 (GIBCO, Grand Island, NY), 80 $\mu \mathrm{g} / \mathrm{ml}$ gentamicin (Schering Corp., Kenilworth, NJ), $300 \mu \mathrm{g}$ of fresh glutamine $/ \mathrm{ml}$, and $10 \%$ heat-inactivated human $\mathrm{AB}$ serum.

\section{Isolation of Lymphocytes}

Peripheral blood mononuclear cells (PBMC) were isolated from heparinized (20 $\mathrm{U} / \mathrm{ml}$ ) venous blood from healthy normal donors using a modified method of Boyum (19). Blood was diluted with an equal volume of normal saline and centrifuged at $400 \mathrm{~g}$ for $30 \mathrm{~min}$ at $18^{\circ} \mathrm{C}$. The mononuclear cell band was harvested, washed three times with saline, and resuspended in complete medium as described (20).

\section{Depletion of Adherent Cells}

PBMC were suspended in complete medium and depleted of adherent cells by passage through a 7-ml column of Sephadex G-10 beads (Pharmacia Fine Chemicals, Piscataway, NJ) equilibrated in complete medium as previously described (5). After $45 \mathrm{~min}$ of incubation at $37^{\circ} \mathrm{C}$, nonadherent peripheral blood lymphocytes (PBL) were eluted with 1 bed volume of medium at $37^{\circ} \mathrm{C}$. Cell recovery was $>70 \%$ of the total input and monocyte contamination as indicated by nonspecific esterase staining was $<2 \%$.

\section{Activation of LAK Cells}

Commercially available recombinant IL-2 (Collaborative Research, Inc., Bedford, MA) was diluted in complete medium and stored at $-70^{\circ} \mathrm{C}$ before use. IL-2 concentrations of $5-10 \mathrm{U} / \mathrm{ml}$ in complete medium (LAK medium) were used to generate LAK cells. PBL were activated to generate LAK cells by in vitro incubation for 5-6 days in LAK medium in upright $25 \mathrm{~cm}^{2}$ flasks at a concentration of $1 \times 10^{6} \mathrm{cells} / \mathrm{ml}$ at $37^{\circ} \mathrm{C}$ in a $5 \% \mathrm{CO}_{2} / 95 \%$ air atmosphere as described (21). 


\section{Experimental Design}

LAK cells were generated in the presence or absence of Con A or PRD in separate experiments. Con A (Difco Laboratories, Detroit, MI) was added to cultures to yield the following final concentrations: $1,5,10,20$, and $40 \mu \mathrm{g} / \mathrm{ml}$. Prednisolone sodium phosphate (Merck Sharp and Dohme, West Point, PA) was added in varying concentrations ranging from $10^{-4}$ to $10^{-9} \mathrm{M}$. Both Con $\mathrm{A}$ and PRD were added separately to the reaction mixture of effector and target cells in a $4 \mathrm{hr}{ }^{51} \mathrm{Cr}$ release assay. Lymphocyte cultures were incubated for 5 days with either Con A or PRD. Control cultures received no PRD or Con A. Both treated and control cultures were washed and tested for their cytotoxicity against different target cells. Viability, as measured by trypan blue dye exclusion, always exceeded $85 \%$ for PRD-treated cells and $80 \%$ for Con A-treated cells at the end of a 5- to 6-day culture period.

\section{Tumor Target Cells}

The human erythroleukemia cell line, K562; the histiocytic lymphoma cell line, U937; the T leukemia cell line, HSB; and the B leukemia cell line, SB; were used as targets in cytotoxicity tests. K562, U937, and HSB are NK sensitive targets while SB is an NK-resistant cell line when used in a $4 \mathrm{hr}{ }^{51} \mathrm{Cr}$ release assay. All target cells were maintained in RPMI 1640 medium containing $10 \%$ fetal calf serum with $80 \mu \mathrm{g} / \mathrm{ml}$ gentamicin and $300 \mu \mathrm{g}$ fresh glutamine per milliliter. Target cells were passaged for $48 \mathrm{hr}$ and washed twice with complete medium. To $0.8-\mathrm{ml}$ aliquots of complete medium containing $5 \times 10^{6}$ tumor cells, $200 \mu \mathrm{Ci}$ of ${ }^{51} \mathrm{Cr}$ as sodium chromate (New England Nuclear, Boston, MA) was added as described (20). The cells were incubated at $37^{\circ} \mathrm{C}$ for $1 \mathrm{hr}$ in a humidified atmosphere of $5 \%$ $\mathrm{CO}_{2}$ in air with intermittent shaking. Following incubation, the cells were washed thrce times with complete medium and resuspended to a concentration of $1 \times 10^{5}$ cells $/ \mathrm{ml}$.

\section{Assay for LAK Cell Activity}

The LAK cell cytotoxicity assay was performed as described for the NK assay using a $4 \mathrm{hr}{ }^{51} \mathrm{Cr}$ release technique $(5,6,20)$. A fixed number of viable effector cells in complete medium was added to triplicate cultures of ${ }^{51} \mathrm{Cr}$-labeled targets in V-bottom microtitration plates (CoStar, Cambridge, MA). After centrifugation at $40 \mathrm{~g}$ for $2 \mathrm{~min}$, they were incubated at $37^{\circ} \mathrm{C}$ in a humidified atmosphere of $5 \%$ $\mathrm{CO}_{2}$ in air for $4 \mathrm{hr}$. At the end of incubation, the plates were centrifuged at $400 \mathrm{~g}$ for $10 \mathrm{~min}$ and $100 \mu \mathrm{l}$ aliquots were removed from each well, transferred to glass tubes, and read in a Packard Model 593 gamma counter. Percent cytotoxicity was calculated as

$$
\% \text { cytotoxicity }=\frac{\text { experimental release }- \text { spontaneous release }}{\text { total release }- \text { spontaneous release }} \times 100,
$$

where spontaneous release represents counts released from control wells containing $1 \times 10^{4}$ target cells, and total release represents counts obtained from an aliquot of $1 \times 10^{4}$ target cells. 
Statistical Analysis

The statistical significance of differences in mean values was determined by a single tail Student's $t$ test and the difference was considered significant when $P$ values were less than 0.05 .

\section{RESULTS}

\section{Effect of Con A on the Generation of LAK Cells}

In view of our earlier findings that PBL precultured with Con A demonstrated decreased NK and ADCC activities (8), experiments were performed to investigate whether Con $\mathrm{A}$ affects the in vitro generation of LAK cells. Figure 1A demonstrates the cytotoxic activity of LAK cells against K562 and U937 targets at a 10:1 effector to target (E:T) cell ratio. LAK cell activity was significantly
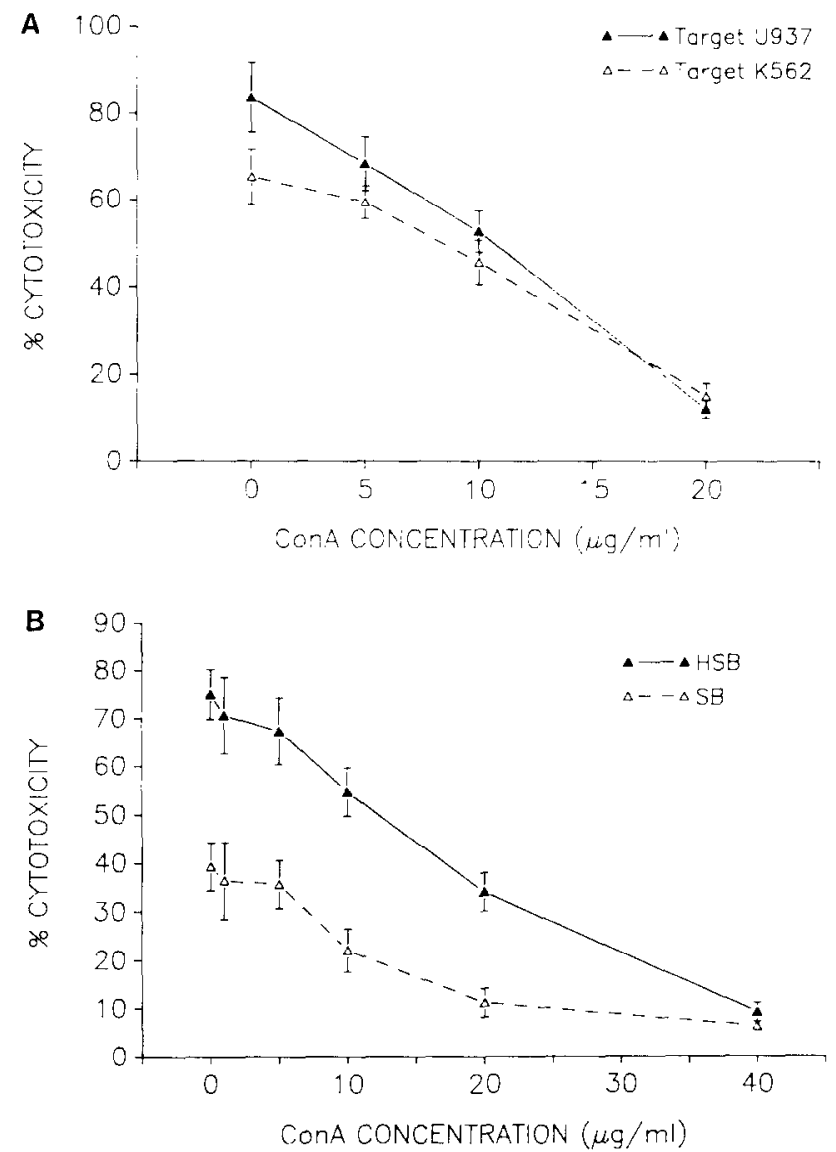

Frg. 1. Effect of Con A on LAK cell generation. Normal PBL $\left(1 \times 10^{6}\right.$ cells $\left./ \mathrm{ml}\right)$ were cultured in IL-2- containing medium (5-10 U/ml) for 6 days with or without varying concentrations of Con A, washed, and tested for their cytotoxic activities against several different target cells. (A) K562 and U937 cells were used as targets at a 10:1 E:T ratio. (B) SB and HSB cells were used as targets at a 100:1 E:T ratio. The variability of the cytotoxicity reaction was always between $5-10 \%$. 
reduced in a dose-dependent manner when Con $\mathrm{A}$ was added to the IL2-containing media at the initiation of LAK cell generation. Con A at 5, 10, and 20 $\mu \mathrm{g} / \mathrm{ml}$, respectively, produced $59 \%(P<0.1), 45 \%(P<0.05)$, and $15 \%(P<$ $0.001)$ cytotoxicity against K562 targets and $68 \%(P<0.1), 52 \%(P<0.025)$, and $12 \%(P<0.001)$ cytotoxicity against U937 targets as compared to untreated LAK cell controls. Figure 1B shows the cytotoxic activity of LAK cells generated with or without varying concentrations of Con A against NK insensitive (SB) and NK sensitive (HSB) target cells at a 100:1 E:T cell ratio. LAK cells generated in medium containing 1 and $5 \mu \mathrm{g}$ Con $\mathrm{A} / \mathrm{ml}$ produced slightly lower levels of cytotoxicity, 35 and $35 \%$ against SB and 70 and $67 \%$ against HSB targets, respectively, compared to untreated LAK cells. Con A at higher concentrations, 10, 20, and 40 $\mu \mathrm{g} / \mathrm{ml}$, manifested $22 \%(P<0.05), 11 \%(P<0.005)$, and $6 \%(P<0.0025)$ cytotoxicity against SB targets and 54\% $(P<0.05), 34 \%(P<0.0025)$, and 9\% $(P<$ 0.0005 ) against HSB cells compared to higher cytotoxic activities produced by control cultures. Data presented in Fig. 2 demonstrate the cytotoxic activity of LAK cells generated in medium containing $20 \mu \mathrm{g}$ Con A/ml against SB and HSB targets at E:T cell ratios ranging from 100:1 to 12.5:1. PBL precultured in LAK medium alone produced $74,73,65$, and $40 \%$ cytotoxicity against HSB targets at $100: 1,50: 1,25: 1$, and 12.5:1 E:T cell ratios, respectively, compared to significantly lower cytotoxicities of $36 \%(P<0.01), 34 \%(P<0.01), 15 \%(P<0.001)$, and $8 \%(P<0.001)$ produced by PBL precultured with Con A in LAK medium. PBL precultured in LAK medium alone produced $40,38,30$, and $22 \%$ cytotoxicity against SB targets at 100:1, 50:1, 25:1, and 12.5:1 E:T cell ratios, respectively, compared to significantly reduced levels of cytotoxicity, $18 \%(P<0.01), 13 \%(P$ $<0.01), 6 \%(P<0.005)$, and $4 \%(P<0.005)$ produced by LAK cells generated in

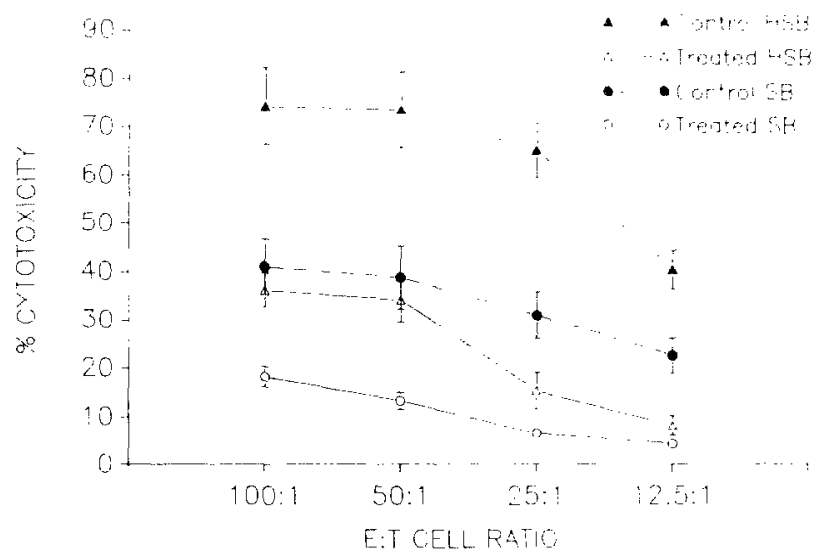

FIG. 2. Effect of Con A on LAK cell activity at various E:T cell ratios. Normal PBL $\left(1 \times 10^{6}\right.$ cells $/ \mathrm{ml}$ ) were cultured in IL-2-containing medium for 6 days with and without $20 \mu \mathrm{g} \mathrm{Con} \mathrm{A/ml} \mathrm{and}$ tested for their cytotoxic activities against SB and HSB targets. (A), Cytotoxicity of PBL precultured without Con A against HSB targets; $(\triangle)$, cytotoxicity of PBL precultured + Con A against HSB targets; (O), cytotoxicity of PBL precultured without Con A against SB targets; $(O)$, cytotoxicity of PBL precultured + Con A against SB targets. Values represent mean percentage cytotoxicity \pm SD of three experiments performed in triplicate. 
LAK medium containing Con A. These results demonstrate that at all E:T cell ratios LAK cells generated with Con A produced lower levels of cytotoxicity compared to untreated cultures and these depressed levels of cytotoxicity were more pronounced at lower E:T cell ratios. Further, we examined the effect of direct addition of Con A on the cytotoxic activity of LAK cells. At a 5:1 E:T cell ratio, fresh lymphocytes demonstrated $11 \%$ cytotoxicity against K562 target cells. Lymphocytes precultured with IL2 for 6 days (LAK cells) produced 29\% cytotoxicity against K562 target cells at a $5: 1 \mathrm{E}: \mathrm{T}$ cell ratio. Con A added directly to the reaction mixture at a concentration of $5 \mu \mathrm{g} / \mathrm{ml}$ produced a negligible decrease ( $26 \%$ cytotoxicity) in the activity of LAK cells. Con A at higher concentrations of 10,20 , and $40 \mu \mathrm{g} / \mathrm{ml}$ produced slight increases in cytotoxicity, $32 \%, 34 \%$, and $35 \%$, respectively, compared to $29 \%$ cytotoxicity manifested by untreated LAK cells. To determine whether Con A-induced suppressor cells were responsible for the inhibition of LAK cell activity, Con A-treated PBL were added to LAK cells in mixing experiments. Data presented in Table 1 demonstrate that Con Aactivated cells at a 1:1 effector to inhibitor cell ratio produced negligible inhibition of the cytotoxicity of LAK cells. Additional experiments were performed to determine whether Con A-activated cells can themselves exert cytotoxic activities thus potentially causing the lysis of LAK cells. Con A-treated cells were also examined for the expression of determinants recognized by LAK cells thus resulting in cold target competitive inhibition of LAK cells. Results presented in Table 2 demonstrate that Con A-treated cells did not produce any cytotoxicity against LAK cells or were Con A-activated PBL subject to lysis by LAK cells.

\section{Effect of Prednisolone on LAK Cells}

IL-2 and LAK cells administered for the experimental treatment of malignancies has been associated with toxic reactions which could be reduced by the coadministration of cortisone acetate (18). We previously reported that IL-2 can

TABLE 1

Con A Activated PBL as Inhibitors of LAK Cell Activity ${ }^{a}$

\begin{tabular}{lccc}
\multicolumn{1}{c}{ Effector cells ${ }^{b}$} & Target cells & \% Cytotoxicity & \% Inhibition \\
\hline LAK cells & SB cells & $38.7^{c}$ & - \\
$\begin{array}{l}\text { Con A-treated PBL } \\
\text { LAK cells } \\
\quad \text { SB cells } \\
\begin{array}{c}\text { Con A-treated PBL } \\
\text { S }\end{array}\end{array}$ & SB cells & 9.3 & - \\
\hline
\end{tabular}

${ }^{a}$ Total PBL $\left(2 \times 10^{6}\right.$ cells $\left./ \mathrm{ml}\right)$ were precultured with $40 \mu \mathrm{g} / \mathrm{ml}$ Con A for 5 days, washed, and used as inhibitors in LAK cell assays at a 1:1 effector to inhibitor ratio in a ${ }^{51} \mathrm{Cr}$ release assay.

${ }^{b}$ PBL precultured with IL-2 for 6 days and used as LAK cells.

${ }^{c}$ Target cells labeled with ${ }^{51} \mathrm{Cr}$ as described under Materials and Methods.

${ }^{d}$ Cytotoxicity was calculated as described under Materials and Methods. Values represent the mean of triplicate determinations of a representative experiment at a 50:1 E:T cell ratio. Two other experiments produced similar results.

${ }^{e}$ Data in parentheses represent the predicted value which is the sum of cytotoxicities of LAK cells + Con A-treated PBL.

${ }^{f}$ Percentage inhibition was calculated on the basis of predicted cytotoxicity as the control. 
TABLE 2

Cultured Cells as Effectors or Targets of Cytotoxicity ${ }^{4}$

\begin{tabular}{llc}
\hline \multicolumn{1}{c}{ Effector cells } & \multicolumn{1}{c}{ Target cells $^{b}$} & $\%$ Cytotoxicity \\
\hline Con A-activated PBL & LAK cells & $2.7^{c}$ \\
LAK cells & Con A-activated PBL & 3.1 \\
LAK cells & Prelabeled SB cells & 42.1 \\
\hline
\end{tabular}

${ }^{a}$ PBL precultured with either Con A $(40 \mu \mathrm{g} / \mathrm{ml})$ (Con A-activated cells) or IL-2 (LAK cells) for 6 days and used either as effector or target cells in a ${ }^{51} \mathrm{Cr}$ release assay at a 50:1 E:T cell ratio.

${ }^{b}$ Target cells labeled with ${ }^{51} \mathrm{Cr}$ as described under Materials and Methods.

${ }^{c}$ Percentage cytotoxicity was calculated as described under Materials and Methods. Values represent the mean of triplicate determinations of a representative experiment. Two other experiments produced similar results.

partially reverse the suppression of NK activity induced by PRD (5). Experiments were thus undertaken to investigate whether PRD directly affects the activity of LAK cells or prevents their generation. Figure 3 shows the effect of direct addition of PRD on the cytotoxic activity of LAK cells against K562 targets in a $4 \mathrm{hr}$ ${ }^{51} \mathrm{Cr}$ release assay. At a 5:1 E:T cell ratio, LAK cells produced a mean of $30 \%$ cytotoxicity. PRD at $10^{-8}, 10^{-7}$, and $10^{-6} M$ concentrations produced negligible inhibition of the cytotoxic effect of LAK cells, 25\% $(P<0.25), 24 \%(P<0.1)$, and $23 \%(P<0.1)$, respectively. PRD at $10^{-5}$ and $10^{-4} M$ concentrations significantly inhibited LAK cell activity, $21 \%(P<0.05)$ and $10 \%(P<0.01)$, respectively.

\section{Effect of Prednisolone on the Generation and Activity of LAK Cells}

Figure 4 demonstrates the viability and yield of LAK cells generated in LAK medium with or without varying concentrations of PRD added at initiation of culture. PBL were cultured initially at a concentration of $1 \times 10^{6}$ cells $/ \mathrm{ml}$. On Day

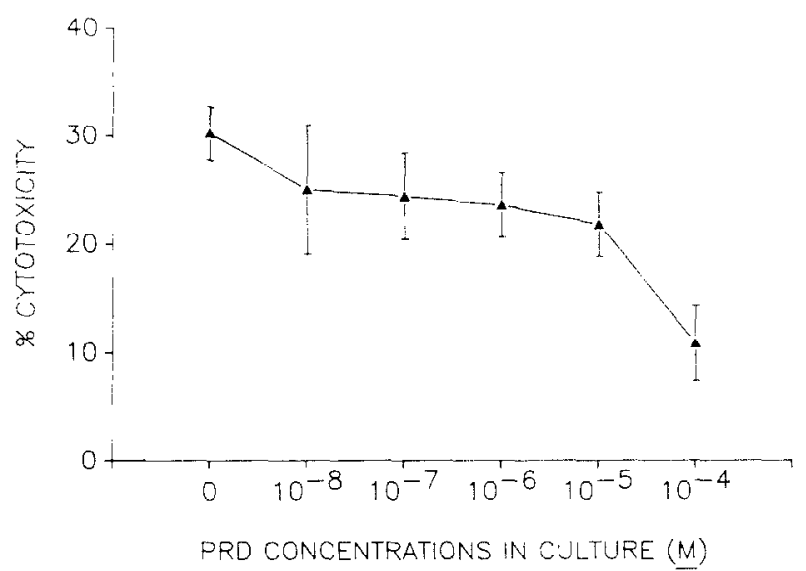

FIG. 3. Effect of prednisolc ne on LAK cell activity. Normal PBL $\left(1 \times 10^{6}\right.$ cells $\left./ \mathrm{ml}\right)$ were cultured in LAK medium with or without varying concentrations of PRD for 6 days, washed, and tested for their cytotoxic activities against $\mathrm{K} 562$ target cells at a 5:1 E:T cell ratio. Values represent mean percentage cytotoxicity \pm SD of three experiments performed in triplicate. 


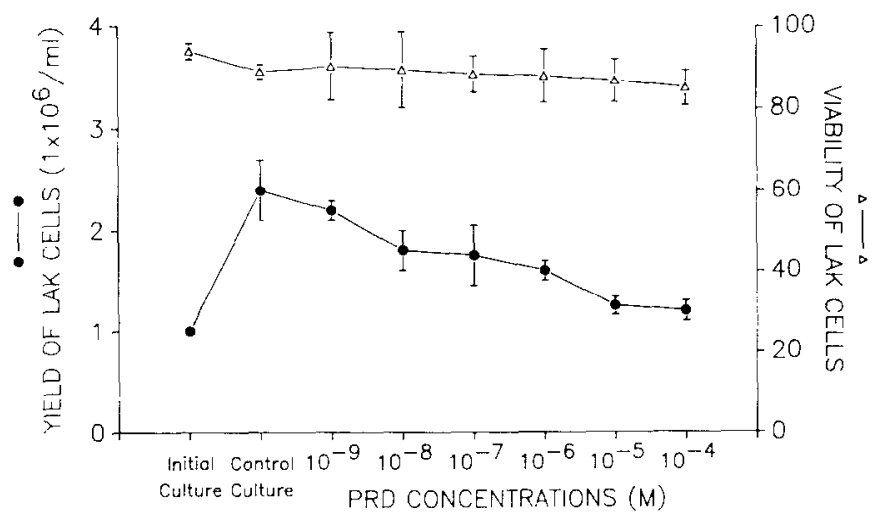

FIG. 4. Effect of prednisolone on yield and viability of LAK cells. Normal PBL $\left(1 \times 10^{6} \mathrm{cells} / \mathrm{ml}\right)$ were cultured in LAK medium for 6 days with or without varying concentrations of PRD, and assayed for yield and viability by trypan blue dye uptake. Values represent mean values \pm SD of two experiments performed in triplicate.

6 of culture, the cell concentration increased to an average value of $2.4 \times 10^{6}$ cells/ml. Cultures containing different concentrations of PRD showed a gradual dose-dependent decrease in the yield of LAK cells. PBL precultured in LAK medium for 6 days demonstrated a mean of $94.2 \%$ viability compared to a mean of $95.0 \%$ viability shown by initial cultures. PBL cultured with varying concentrations of PRD in LAK medium also showed levels of viability comparable to untreated control cultures at all PRD concentrations tested. Although PRD at doses as low as $10^{9} M$ caused some dimunition of LAK cell yield, a further dose-dependent decrease in the generation of LAK cells was noted with higher concentrations. Viability as determined by trypan blue dye uptake was unaffected by the concentration of PRD used.

Figure 5 shows the cytotoxic activity of LAK cells generated in the presence of different concentrations of PRD against target cells. At PRD concentrations of $10^{-8}$ and $10^{-7} M$, LAK cells demonstrated a slight inhibition of their cytotoxicity, $54 \%(P<0.4)$ and $45 \%(P<0.1)$, respectively. PRD at $10^{-6}$ and $10^{-5} M$ significantly inhibited LAK cell activities yielding cytotoxicities of $23 \%(P<0.005)$ and $15 \%(P<0.0025)$, respectively. LAK cells generated with PRD concentrations of $10^{-7}, 10^{-6}$, and $10^{-5} M$ manifested significantly lower levels of cytotoxicity against K562 targets, 30\% $(P<0.05), 25 \%(P<0.025)$, and $10 \%(P<0.001)$, respectively, compared to controls. PRD at concentrations of $10^{-9}, 10^{-8}, 10^{-7}$, $10^{-6}$, and $10^{-5} M$ also produced significantly lower levels of cytotoxicity, $25 \%$ ( $P$ $<0.025), 18 \%(P<0.025), 12 \%(P<0.01), 10 \%(P<0.0025)$, and $5 \%(P<0.001)$, respectively, compared to $45 \%$ cytotoxicity expressed by untreated cultures against HSB target cells at 10:1 E:T ratios. LAK cells generated in media alone produced $21 \%$ cytotoxicity against SB targets which was significantly reduced to $11 \%(P<0.05), 7 \%(P<0.025), 5 \%(P<0.01), 4 \%(P<0.005)$, and $2 \%(P<$ 0.0025 ) cytotoxicity by $10^{-9}, 10^{-8}, 10^{-7}, 10^{-6}$, and $10^{-5} M$ PRD concentrations, respectively. Data in Fig. 6 demonstrate LAK cell activity of PBL precultured in LAK medium with or without $10^{-7} M$ PRD at different E:T ratios. LAK cells 


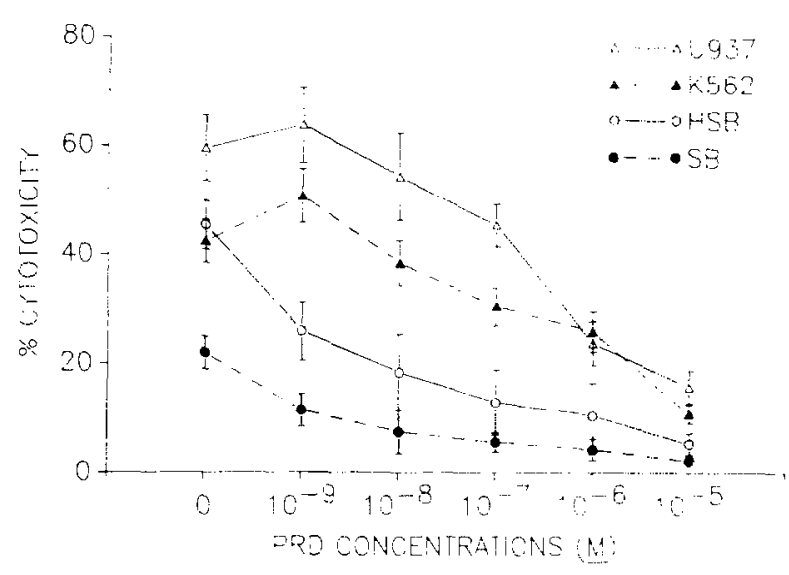

FIG. 5. Effect of prednisolone on LAK cell generation. Normal PBL $\left(1 \times 10^{6} \mathrm{cells} / \mathrm{ml}\right)$ were cultured in LAK medium for 6 days with or without varying concentrations of PRD, washed, and tested for cytotoxic activity against the various targets indicated at 10:1 E:T cell ratios. Values represent mean percentage cytotoxicity \pm SD of three experiments performed in triplicate.

generated without PRD produced 62,50 , and $24 \%$ cytotoxicity at $25: 1,10: 1$, and 5:1 E:T cell ratios, respectively, against K562 targets compared to significantly lower levels of cytotoxicity, 44\% $(P<0.05), 25 \%(P<0.025)$, and $10 \%(P<$ $0.025)$ produced by LAK cells generated with PRD. When the SB cell line, known to be nonsensitive to NK cells, was used as targets of LAK cells generated without PRD, 28, 22, and $15 \%$ cytotoxicity was observed at 25:1, 10:1, and 5:1 E:T cell ratios, respectively. However, LAK cells generated in the presence of $10^{-7} M$ PRD manifested significantly decreased levels of cytotoxicity, $13 \%(P<$

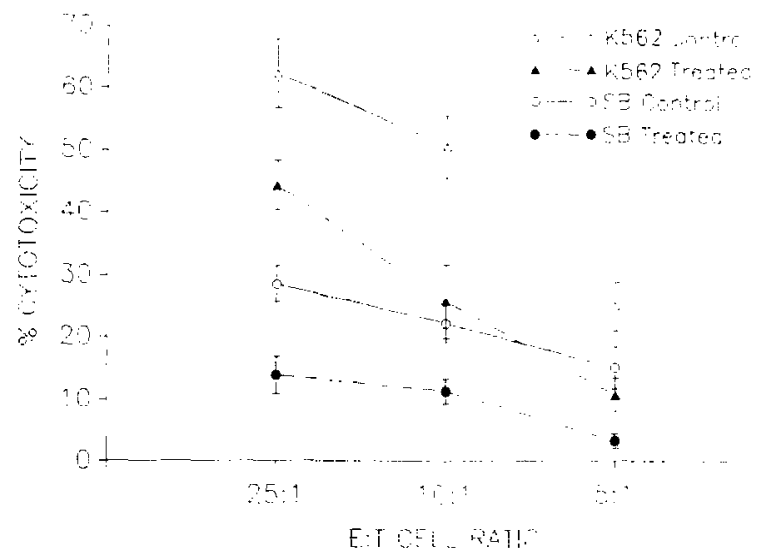

FIG. 6. Effect of prednisolone on LAK cell activity at various E:T cell ratios. Normal PBL $\left(1 \times 10^{\mathrm{h}}\right.$ cells $/ \mathrm{ml}$ ) were cultured in LAK medium for 6 days with or without $10^{-7} M$ PRD, washed, and tested for their cytotoxic activity against K562 and SB targets. Values are mean cytotoxicity \pm SD of three experiments with triplicate de erminations each. $(\triangle)$. Cytotoxicity of PBL precultured without PRD against K562 targets; ( $\triangle$ ), cytotoxicity of PBL precultured + PRD against K562 targets; (O). cytotoxicity of PBL precultured without PRD against SB targets; $(\mathbf{O})$, cytotoxicity of PBL precultured + PRD against SB targets. 
$0.025), 11 \%(P<0.025)$, and $3 \%(P<0.025)$ at $25: 1,10: 1$, and 5:1 E:T cell ratios, respectively. Thus inhibition of LAK cell cytotoxicity by PRD was evident through a wide range of E:T cell ratios.

\section{DISCUSSION}

In a variety of animal and human studies, lectins and corticosteroids were observed to exert a major role in nonspecific immunoregulation (22-24). Our previous investigations demonstrated that PBL precultured with Con A exhibited diminished NK and ADCC activities and could suppress these cytotoxic functions in both autologous and allogeneic coculture experiments, and regulation of these cytotoxic activities appears to be mediated by soluble factors released by Con A-activated cells (8). We also demonstrated that PRD significantly inhibited the NK and ADCC activities of normal lymphocytes in vitro (5).

LAK cells have been gaining importance because of their apparent role in host defense against tumors. The concept of adoptive immunotherapy in tumor control has been strengthened recently by the demonstration that LAK cells can kill a variety of tumor cells (10-15), although normal fetal and placental cells also showed susceptibility to lysis by LAK cells (14). It has been reported that the in vivo use of LAK cells for experimental tumor therapy can be associated with a toxic effect, the capillary permeability leak syndrome, which could be ameliorated by administration of steroids (18). To make LAK cell therapy a success, a precise understanding of the cellular and molecular mechanisms of their immunoregulation must be developed. We report herein a previously unrecognized immunoregulatory aspect of LAK cell activity, Con A and PRD suppress the induction as well as the lytic ability of LAK cells against a variety of target cells in vitro.

The concentration of IL-2 used in the present investigation is less than that generally used in the most recent LAK cell generation protocols using 1 or 2 days of culture. Our protocol is consistent, however, with the earlier studies of Grim and Rosenberg (14) who used very low concentrations of IL-2 to generate LAK cells over a longer period of 4 to 5 days of incubation. Further, our earlier studies showed that Con A and PRD exert immunomodulatory effects on NK cells when lymphocytes were precultured for $72 \mathrm{hr}$. Therefore generation of LAK cells using low concentrations of IL - 2 in a 4- to 5-day culture may be a preferable model to study the effects of these agents on LAK cell generation and activity.

The mechanism by which Con A inhibits LAK cells is not yet understood. We examined whether Con A may induce suppressor cells capable of inhibiting LAK cell induction or function. In coculture experiments, Con A-treated, allogeneic lymphocytes did not significantly inhibit the cytotoxic activities of LAK cells (Table 1), thus demonstrating that unlike many other lymphoid functions, LAK cells are not regulated by Con A-induced suppressor $\mathrm{T}$ cells. It is also possible that Con A may be inducing autoreactive cytotoxic cells, leading to lysis of LAK cells or may be stimulating the expression of additional LAK cell-specific target determinants thus potentially causing cold target competitive inhibition of LAK cells. Our data show that Con A-treated cells produced no cytotoxic activity against ${ }^{51} \mathrm{Cr}$-labeled LAK cells nor did they themselves serve as targets of LAK 
cells causing cold target competitive inhibition (Table 2). The direct addition of Con A to the LAK and target cell mixture showed a moderate enhancement of LAK cell activity which is consistent with lectin-dependent cellular cytotoxic activity as reported earlier by us $(25,26)$ and others $(27,28)$. The reduced cytotoxic activity of LAK cells generated in the presence of Con A compared to control cultures containing only IL-2 was not merely due to a decrease in cell number as equal numbers of viable effector cells from Con A-treated and control cultures were used in the assay. Thus the inhibition of LAK cell generation and activity may be due to the direct effect of Con A on LAK cells or their precursors or through some soluble immunoregulatory mediators produced by Con A directed against LAK cells or their precursors. Further experiments may resolve this issue.

Numerous studies have shown that steroids act on macrophages, $T$ and $B$ lymphocytes, and NK cells (29-34). This report further demonstrates that PRD exerts an inhibitory effect on LAK cell generation and activity. While a negligible inhibitory effect was noted at $10^{-9}$ and $10^{-8} M$ PRD, higher concentrations, $10^{-7}$, $10^{-6}$, and $10^{-5} M$, significantly inhibited the generation of LAK cells. When PRD was added directly to the mixture of LAK cells and target cells in the cytotoxicity assay, significant inhibition was observed only at the higher steroid concentrations. The inhibitory effect of PRD on LAK cell activity was not due to increased resistance of targets to lysis as target cells pretreated with PRD were as sensitive to lysis as untreated targets (data not shown). Papa et al. (18) reported that systemic administration of daily doses of cortisone reduced the toxicity resulting from high doses of IL-2. Similar doses of cortisone did not effect the therapeutic effect of administration of exogenous LAK cells plus low doses of IL-2. Using an in vitro system, Papa et al. (18) also observed a decreased yield of LAK cells when cortisone acetate was added directly to the LAK cell generation cultures. Our results herein are consistent with the in vitro observations of Papa et al. (18) as the addition of PRD to LAK cell generation cultures resulted in a reduction of LAK cell yields. Further, we demonstrated that the specific cytotoxic activity, on a per cell basis, of PRD-treated LAK cells was also decreased. This, however, contrasts with Papa et al. (18) who showed that the lytic activity per cell was not changed by incubation with cortisone acetate. This discrepancy may be due to potential differences between the immunoregulatory effects of cortisone acetate and PRD. Another mechanism which could result in a lower yield of LAK cells is the direct lysis of lymphocytes by PRD. However, this is unlikely since PRD, even at higher concentrations, did not cause any loss of viability as shown in Fig. 4.

The mechanisms by which PRD affects LAK cell activity are also not well understood. Palacios and Sugawara (23) demonstrated that hydrocortisone inhibits the proliferation of $\mathrm{T}$ cells in the autologous-mixed lymphocyte reaction by causing IL-2 producing T cells to become unresponsive to IL-1 and therefore unable to synthesize IL-2. Although exogeneous IL-2 is available in the LAK cell culture, precursor cells cannot respond to IL-2 stimulation as indicated by the lower yield of LAK cells generated in the presence of PRD as well as their decreased functional activity. We reported earlier that PRD-induced inhibition of 
NK and ADCC activities was not significantly reversed by the addition of exogenous IL-2 (5). Future studies may elucidate the cellular and biochemical mechanisms underlying PRD-induced suppression of LAK cell generation and function. To achieve an effective antitumor response in adoptive immunotherapy using LAK cells, special consideration should be given to the coadministration of corticosteroids. These in vitro effects of PRD on LAK cell activity may be a reflection of similar immunological changes occurring in vitro, however, caution should be exercised for the direct extrapolation of these in vitro results to more complex in vivo situations.

\section{REFERENCES}

1. Herberman, R. B., In "NK and Other Effector Cells," Academic Press, New York, 1980.

2. Welsh, R. M., Curr. Top. Microbiol. Immunol. 92, 83, 1981.

3. Nair, M. P. N., Fernandes, A., Onoe, K., Day, N. K., Good, R. A., Int. J. Cancer 25, 667-677, 1980.

4. Cudkowicz, G., and Hochman, P. S., Immunol. Rev. 44, 13, 1979.

5. Nair, M. P. N., and Schwartz, S. A., Immunology 132, $2876,1984$.

6. Nair, M. P. N., Schwartz, S. A., Fernandes, G., Pahwa, R., Ikehara, S., and Good, R. A., Cell. Immunol. 58, 6, 1981.

7. Pollack, S. B., and Emmons, S. I., J. Immunol. 122, 718, 1979.

8. Nair, M. P. N., and Schwartz, S. A., J. Immunol. 126, 2221, 1981.

9. Nair, M. P. N., and Schwartz, S. A., J. Allergy Clin. Immunol., in press.

10. Rosenberg, S. A., Lotze, M. T., Muul, L. M., Leitman, S., Chang, A. E., Ettinghausen, S. E., Matory, Y. L., Skibber, J. M., Shiloni, E., Vetto, J. T., Seipp, C. A., Simpson, C., Reichert, C. M., N. Engl. J. Med. 313, 1485, 1985.

11. Rosenberg, S. A., Lotze, M. T., Muul, L. M., Leitman, S., Chang, A. E., Vetto, J. T., Seipp, C. A., and Simpson, C., Surgery 100, 262, 1986.

12. Rosenberg, S. A., Spiess, P., and Lafreniers, R., Science 233, 1318, 1986.

13. Andriole, G. L., Mule, J. J., Hansen, C. T., Linehan, W. M., Rosenberg. S. A.. J. Immunol. 135, $2911,1985$.

14. Grimm, E. A., and Rosenberg, S. A., In "Lymphokines" (E. Pick, Ed.), p. 279, Academic Press, New York, 1986.

15. Rosenberg, S. A., Spiess, P., and Lafreniere, R., Science 233, 1318, 1986.

16. Damle, N. K., Doyle, L. V., and Bradley, E. C., J. Immunol. 137, 2814, 1986.

17. Gray, J. G., Shau, H., and Golub, S. H., Cell. Immunol. 96, 338, 1985.

18. Papa, M. Z., Vetto, J. T., Ellinghauson, S. F., Mule, J. J., and Rosenberg, S. A., Cancer Res. 46, $5618,1986$.

19. Boyum, A., J. Clin. Lab. Invest., 21, 77, 1968.

20. Nair, M. P. N., Cilik, J. M., and Schwartz, S. A., J. Immunol. 136, 2456, 1986.

21. Rayner, A. A., Grim, E. A., Lutze, M. T., Chu, E. W., and Rosenberg, S. A., Cancer 55, 1327, 1985.

22. Fauci, A. S., and Dale, D. C., Blood 46, 235, 1974.

23. Palacios, R., and Sugawara, I., Scand. J. Immunol. 15, 25, 1982.

24. Shou, L., Schwartz, S. A., and Good, R. A., J. Exp. Med. 143, $1100,1976$.

25. Brunda, M., Varesio, L., Herberman, R. B., and Holden, H. T., Int. J. Cancer 29, 299, 1982.

26. Spits, H., Borst, J., Teahorst, C., and DeVris, J. E., J. Immunol. 129, 1563, 1982.

27. Nair, M. P. N., Lewis, E. W., and Schwartz, S. A., J. Clin. Immunol. 6, 363, 1986.

28. Nair, M. P. N., Schwartz, S. A., and Menon, M., Cell. Immunol. 94, 159, 1985.

29. Munk, A., and Leung, K., In "Receptors and Mechanisms of Action of Steroid Hormones, Part II"' (J. R. Pasqualini, Ed.), p. 311, Dekker, New York, 1977.

30. Gupta, S., Schwartz, S. A., and Good, R. A., Cell. Immunol. 44, 242, 1979. 
31. Kurnick, J. T., Kradin, R. L., Blumberg, R., Schneeberger, E. E., and Boyle, L. A., Clin. Immunol. Immunopathol. 38, 367, 1986.

32. Haynes, B. F., and Fauci, A. S., J. Immunol. 121, 559, 1978.

33. Smith, D. A., Crabtree, G. R., Kennedy, S. J., and Munk, A.. Nature (London) 267, 523, 1977.

34. Bach, J. F., Duval, D., Dardenne, M., Salomon, J. C., Tursz, T. A., and Fournier, C., Transplant. Proc. 8, 25, 1975.

35. Gillis, S., Crabtree, G. R., and Smith, K. A., J. Immunol. 123, 1624, 1979.

Received December 1, 1987; accepted with revision May 5, 1988 